\title{
Evaluation of quality of life and functionality of patients chronic renal in hemodialysis treatment
}

\begin{abstract}
Introduction: Chronic Renal Disease (CKD) is an insidious, asymptomatic, progressive and irreversible renal damage. Added to hemodialysis treatment triggers negative effects on the cardiorespiratory, musculoskeletal system and quality of life (QOL). Therefore, we sought to evaluate functionality, quality of life and respiratory muscle strength and peak expiratory flow in patients with chronic renal failure on hemodialysis.
\end{abstract}

Materials and methods: A cross-sectional and descriptive study, with a convenience sample of 30 individuals. An individual identification form, the Kidney Disease and Quality-of-Life Short-Form (KDQOL- SF) quality of life assessment instrument and the Functional Independence Measure (FIM) instrument were used. Also, specific tests for evaluation of respiratory muscle strength (RMS) and peak expiratory flow (PEF).

Results: A homogeneous sample characterized as old adults with low schooling, and mostly hypertensive and diabetic. Individuals with complete functional independence (FIM: 118.13 \pm 17.1 ). There was a great decline in respiratory muscle strength and peak expiratory flow, about $40-50 \%$ of predicted values. With significant impact on the situation of work and sexual function, $25 \pm 42.9$ and $45.5 \pm 44.3$, respectively. Positive values were obtained on social interaction and stimulation by the dialysis team.

Conclusion: It was concluded that there are no impacts on its functionality. However, there is a significant decline in respiratory functional parameters, such as respiratory muscle strength and peak expiratory flow, as well as in the health-related quality of life of chronic renal patients undergoing hemodialysis treatment.

Keywords: renal failure, renal dialysis, chronic disease, maximum respiratory pressures, quality of life

\section{Introduction}

Chronic non-communicable diseases (CNCD) have increased in prevalence over the years, generating increasing economic, social, comorbidity development and public health spending problems. In addition, their negative impact on the functionality and quality of life related to the health of patients (QOLRH) has drawn the government's attention, leading it to create public policies that promote health, prevent diseases and increase quality of life. ${ }^{1,2}$ Cardiovascular and respiratory diseases are the most frequent among CNCDs, having a close relationship with Chronic Renal Disease (CRD). According to the 2017 Census of the Brazilian Society of Nephrology (BSN) ${ }^{3}$, the national estimate of the prevalence and incidence rate of patients with CRD on dialysis was 610 patients per million of the population (pmp) and $193 \mathrm{pmp}$, respectively. Some risk factors are prone to the onset of CRD, such as hypertension, diabetes, aging and use of nephrotoxic medications. ${ }^{4} \mathrm{CRD}$ is insidious, asymptomatic, progressive and irreversible renal damage. It is usually identified from decreased markers in the glomerular filtration rate (GFR) and/ or renal parenchymal injury, present for 3 or more months. It is also associated with loss of regulatory functions, excreta and endocrine in the kidney. ${ }^{5,6} \mathrm{~A}$ state of deconditioning, muscle fatigue, asthenia, dyspnea, muscle weakness, skin discoloration, weight loss and edema, resulting from chronic kidney disease in association with lung alterations and musculoskeletal degradation, is established. The sum of these factors, which present interrelationship and feedback, directly interferes with QOLRH, functionality and condition of the body image (use of arteriovenous fistula (AVF). There is loss of autonomy for usual activities, modification of the economic (financial) state. Regular dialysis treatment, usually performed three times/week for about 3 to $4 \mathrm{~h} /$ day, contributes to de-socialization. New eating habits

\author{
Volume 9 Issue I - 202|
}

\author{
Vitória Suyane Ferreira da Cruz,' \\ Glaucimária Santana Santos, ${ }^{2}$ Yago Alves \\ Lima, ${ }^{3}$ Lucas Aragão da Hora Almeida, ${ }^{4}$ \\ Carlos José Oliveira de Matos ${ }^{5}$ \\ 'Physiotherapist, Federal University of Sergipe, Brazil \\ ${ }^{2}$ Degree of Physiotherapy, Federal University of Sergipe, Brazil \\ ${ }^{3}$ Physiotherapist, Federal University of Sergipe, Brazil \\ ${ }^{4} \mathrm{PhD}$ in Genetics and Molecular Biology, Santa Cruz State \\ University, Brazil \\ ${ }^{5}$ Master and PhD in Health Sciences, Federal University of \\ Sergipe, Brazil
}

\begin{abstract}
Correspondence: Vitória Suyane Ferreira da Cruz, Federal University of Sergipe,Av. Gov. Marcelo Déda - São José, Lagarto, Sergipe, Brazil, (79) 3632-2082, Email suyane.q@gmail.com
\end{abstract}

Received: April 20, 2020 | Published: February 26, 2021 must be established and the deficit in physical capacity and mental health must be considered. The vicious circle of reduced functional capacity, respiratory muscle function and overall muscle strength of patients should be disrupted. ${ }^{7,8}$ This study aimed to evaluate the quality of life and functionality of patients with chronic renal failure in hemodialysis treatment, considering the level of functional independence, respiratory functional parameters, comparing the values obtained with the predicted values, as well as correlating them to the time they underwent hemodialysis and their comorbidities. In addition, to investigate the relation of time of hemodialysis and associated diseases in the quality of life in chronic renal patients.

\section{Material and methods}

Cross-sectional survey, with samples obtained at Hospital do Rim de Sergipe, located at Rua Arauá, 02-41- Centro, Aracaju - SE, CEP: 49010-330. The sample was of 30 adult individuals of both sexes, over 40 years of age. Those with a clinical diagnosis of CRD in hemodialysis treatment for at least 6 months and who agreed to participate in the study by signing the Free and Informed Consent Form $(\mathrm{FICF})^{9}$ were included. The exclusion criteria were related to hemodynamic instability (severe cardiovascular and respiratory diseases), presence of physical or mental disability and osteomuscular diseases such as arthritis, osteoporosis, fractures, injuries or trauma. An identification sheet (Appendix II), the Functional Independence Measurement Instrument (FIM) ${ }^{10}$ and the Kidney Disease and Qualityof-Life Short-Form (KDQOL-SF) questionnaire (Appendix II) ${ }^{11}$ were used for data collection. Also the specific tests such as the assessment of respiratory muscle strength, through manovacuometry ${ }^{12}$ and the test of respiratory effectiveness, through peak expiratory flow with Peak Flow Meter ${ }^{\circledR 3}{ }^{13}$. In order to avoid muscle fatigue an evaluation 
sequence was established for all participants, whose sequence started from the explanation of the objectives of the research $\rightarrow$ signature of the FICF $\rightarrow$ individual identification sheet $\rightarrow$ Functionality Assessment (FIM) $\rightarrow$ Measurement of maximum respiratory pressures (MIP and MEP) $\rightarrow$ Measurement of Quality of Life $\rightarrow$ Peak expiratory flow. The individual's identification sheet, made up by the research, which contains general information about the individual (name, age, gender, time of diagnosis of CRD, time and weekly frequency of hemodialysis treatment, height, body weight, body mass index and associated diseases).

The quality of life of these individuals was verified by the KDQOL-SF questionnaire, with the junction of SF-36 plus 43 items on chronic renal disease specifically. In total there are 19 dimensions (8 general and 11 specific): physical functioning, limitations caused by physical health problems, limitations caused by emotional health problems, social functioning, mental health, pain, vitality (energy/ fatigue), general health perceptions, current health status compared to one year ago, kidney symptoms/problems, effects of kidney disease on daily life, overload imposed by kidney disease, work condition, cognitive function, quality of social interactions, sexual function and sleep. It also includes three additional scales, which are: social support, stimulation of the dialysis team and patient satisfaction. The questionnaire was converted into scores according to recommendations and tables provided by KDQOL Working Group. ${ }^{11}$

According to Hays and employees14, the KDQOL-SF Working Group, the score for each question varies between 0 and 100, with the lower the score the greater the negative impact on the individual's life and the higher the score the greater the positive impact on the individual's life. It is understood that in the final score of each dimension, the closer to the total value (100), the better their quality of life. The functionality evaluated by the Disability and Functionality Measurement instrument (FIM) quantifies, specifically, the performance of a series of motor and cognitive tasks of daily life. The instrument contains questions related to self-care, transference, locomotion, sphincter control, communication and social cognition, including memory, social interaction and problem solving. There are 18 questions, each scoring between 1 and 7 points, total dependence and complete independence, respectively. ${ }^{10}$

Regarding the respiratory functional parameters, the respiratory muscle strength measured by manovacuometry is based on the technique of Neder et al. ${ }^{12}$ the patient performs five Maximum Inspiratory Pressure (MIP) maneuvers and five Maximum Expiratory Pressure (MEP) maneuvers, each of which is maintained for three seconds. To effectively perform the test, the individual remains seated, with the nostrils occluded by a nose clip; the assessor holds the nozzle firmly against the lips, in order to avoid air leakage, in both maneuvers (inspiration and expiration). MIP is measured during effort initiated from residual volume, while MEP during effort initiated from total lung capacity. The value to be considered for analysis of the results will be the highest value obtained for MIP and MEP, counting that the variability between the measures did not exceed $10 \%$ in relation to the highest value obtained. Otherwise, the test must be redone with a rest interval. The formula used to calculate the reference values and those obtained during the collection was also from the study by Neder et al. ${ }^{12}$

\begin{tabular}{lll}
\hline & Women & Men \\
\hline MIP & $y=-0.49($ age $)+110.4$ & $y=-0.80($ age $)+\mid 55.3$ \\
MEP & $y=-0.6|(a g e)+| 15.6$ & $y=-0.8|(a g e)+| 65.3$
\end{tabular}

Legend: MIP,: maximum inspiratory pressure; MEP: expiratory pressure
Finally, analysis of peak expiratory flow, with the volunteer standing, head positioned on the midline and without the use of a nose clip, performs a maximum inspiration, followed by a fast and forced total expiration on the peak flow meter, for 2 seconds, starting from the maximum pulmonary volume. This maneuver is performed 3 times, with an interval of 30 seconds, and if the difference between them is $40 \mathrm{~L} /$ min, 5 maneuvers are performed, and the largest of them is established as a record..$^{13}$ The descriptive statistical analysis is presented as mean \pm standard deviation, relative and absolute frequency, minimum and maximum, and percentage. For quantitative variables, the normality test (Levene) was performed. For other comparison tests between means, parametric data, the student test $(\mathrm{t})$ and the Mann Whitney test $(\mathrm{U})$ for non-parametric data were performed. To correlate the variables we used the Spearman test, considering significant values: $\mathrm{p} \leq 0.05$. There was also verification of data with simple and multiple linear regression for cause and effect relationships. This work was approved by the CEP of the Federal University of Sergipe under CAAE protocol No. 12241019.3.0000.5546, and opinion number 3.423.094.

\section{Results}

A homogeneous sample presenting the mean age of mature adults ( $62 \pm 9.17$ years), having $46.6 \%$ of the sample with more than 8 years of schooling. The analysis of the mean weight and height variables led to a BMI of $25 \pm 4.3 \mathrm{Kg} / \mathrm{m}^{2}$, fitting a population overweight (obesity). The marital status of the sample was indicated as $50 \%$ married (15), $30 \%$ single (9) and $20 \%$ widowed (6). The hemodialysis treatment time was about $49.1 \pm 38.9$ months, with a current frequency of $12 \pm 0.52$ hours per week. Regarding occupation, only $2(6.6 \%)$ individuals still work and the rest are retired. The associated comorbidities are predominantly diabetic and hypertensive (Table 1). The mean respiratory parameters measured were below the predicted values. Due to parametric distribution, the maximum inspiratory pressure data (MIP obtained) were compared from the $t$ test, obtaining $44.71 \%$ $(-41.56 \pm 13.14 \mathrm{cmH} 2 \mathrm{O})$ of that predicted in the literature $(\mathrm{p}<0.01)$. The data of expiratory pressure (MEP obtained), nonparametric, were compared by the Mann Whitney test, and showed a more significant difference between the means, about only $49.45 \%(+47.63 \mathrm{cmH} 2 \mathrm{O})$ of the predicted value $(p<0.01)$. Finally, the peak expiratory flow $(\mathrm{PEF})$, being performed the Mann Whitney test $(\mathrm{p}<0.01)$ and reaches only $47.53 \%(164 \pm 74.83 \mathrm{~L} / \mathrm{min})$ of the expected value in the literature (Table 2)

Table I Presentation of the mean and standard deviation of the general characteristics of these subjects

\begin{tabular}{lll}
\hline Variables & Average & SD \\
\hline Age (Years) & 62 & 9,17 \\
Weight $(\mathrm{Kg})$ & 69,6 & 16,7 \\
Stature $\left(\mathrm{m}^{2}\right)$ & 1,65 & 0,08 \\
BMI $\left(\mathrm{Kg} / \mathrm{m}^{2}\right)$ & 25 & 4,3 \\
THD (Months) & 49,1 & 38,9 \\
FHD (Hours/Week) & 12 & 0,52 \\
Related diseases & $\mathrm{n}$ & $\%$ \\
Hypertension & 14 & 46,7 \\
Diabetes & $\mathrm{I}$ & 3,3 \\
SAH + DM & 8 & 26,7 \\
Comorbidity-free & 7 & 23,3 \\
\hline
\end{tabular}

Legend: SD, standard deviation; F/M, female/male; BMI, body mass index; THD, time of hemodialysis; HDF, frequency of hemodialysis; SAH, systemic arterial hypertension; DM, diabetes melittus 
Table 2 Presentation of means and standard deviations of respiratory muscle strength and peak expiratory flow of individuals in the sample

\begin{tabular}{|c|c|c|c|c|c|c|}
\hline & MIP obtained & MIP predicted & MEP obtained & MEP predicted & PEF obtained & PEF predicted \\
\hline Average $\pm S D$ & $-41,56 \pm 13,14$ & $-92,94 \pm 14,5$ & $47,73 \pm 12,33$ & $96,52 \pm 20,13$ & $164 \pm 74,83$ & $345,8 \pm 19,64$ \\
\hline P & 0,01 & & 0,01 & & 0,01 & \\
\hline
\end{tabular}

Legend: MIP obtained, maximum inspiratory pressure obtained inside the sample; MIP predicted, maximum inspiratory pressure predicted by the literature; MEP obtained, maximum expiratory pressure obtained inside the sample; MEP predicted, maximum expiratory pressure predicted by the literature; PEF obtained, peak expiratory flow peak obtained inside the sample; PEF predicted, Peak expiratory flow predicted by the literature; $p<$, significant value below 0.05

The data of the FIM scale reach, on average, the functional independence classification, and total $118.13 \pm 17.1$ (51-126) points, with no impact on individual domains. The means vary between 6.3 and 6.9 points, in the memory and social interaction dimensions, respectively (Table 3 ). Analyzing quality of life (Table 4), the KDQOL - SF questionnaire is presented in its first 11 domains (specific for chronic renal patients). It shows 3 dimensions with values less than half their score (50 points): (D3) Kidney disease overload, (D4) Work situation and (D7) Sexual function. Table 5 shows the last 8 dimensions (general questions), where it contains the generic part of the SF-36. No domain presented values below 50 points, but obtained 3 dimensions in this range: (D12) Physical function, (D13) Physical function, and (D17) Emotional function. The overall average of the questionnaire resulted just above half the total score (64.5 \pm 16.5$)$. Overall, only two domains were highlighted with high scores: (D6) Quality of social interaction and (D10) Stimulation by the dialysis team, averaging $88 \pm 24.3$ and $87.9 \pm 25.8$, respectively.

Table 3 Presentation of the means and standard deviations of the sample's Independence and Functionality Measure (FIM)

\begin{tabular}{lllllllllll}
\hline VR & SC & TRANS & LOC & SC & CM & CG & ME & SI & PS & Tt \\
\hline AVERAG & 6,5 & 6,73 & 6,45 & 6,63 & 6,7 & 6,43 & 6,33 & 6,93 & 6,3 & 118,13 \\
SD & $\pm I, 5$ & $\pm I, 12$ & $\pm I, 24$ & $\pm I, 4$ & $\pm 0,6$ & $\pm I, 3$ & $\pm 1,5$ & $\pm 0,3$ & $\pm I, 7$ & $\pm 17,1$
\end{tabular}

Legend:VR, variables; SD, standard deviation; AC, self-care; TRANS: transfer; LOC, locomotion; SC, sphincter control; CM, communication; CG, cognition; ME, memory; SI, social interaction; PS, problem solving; Tt, total

Table 4 Presentation of means and standard deviations of the specific domains (II) of the patient quality of life questionnaire (KDQOL-SF)

\begin{tabular}{llllllllllll}
\hline VR & DI & D2 & D3 & D4 & D5 & D6 & D7 & D8 & D9 & D10 & DII \\
\hline AVERAGE & 73,7 & 70,8 & 37,7 & 25 & 81,1 & 88 & 45,5 & 74,2 & 80,6 & 87,9 & 65,5 \\
SD & 34,8 & 37,6 & 44,4 & 42,9 & 28,3 & 24,3 & 44,3 & 33,2 & 32,6 & 25,8 & 27,6
\end{tabular}

Legend:VR, variables; SD, standard deviation; DI, list of symptoms/problems; D2, effects of kidney disease; D3, overload of kidney disease; D4, work situation; D5, cognitive function; D6, quality of social interaction; D7, sexual function; D8, sleepiness; D9, social support; DI0, stimulation by the dialysis team; DI I, Patient satisfaction

Table 5 Presentation of means and standard deviations from the general domains (8) of the quality of life questionnaire (KDQOL-SF) for patients

\begin{tabular}{llllllllll}
\hline VR & DI2 & DI3 & DI4 & DI5 & DI6 & DI7 & DI8 & DI9 & TT \\
\hline AVERAGE & 55,5 & 52,5 & 71,2 & 61,5 & 70,3 & 55,7 & 65,8 & 62,3 & 64,5 \\
SD & 43,6 & 50,1 & 35,1 & 39,4 & 32,4 & 49,8 & 34,1 & 35,7 & 16,5 \\
\hline
\end{tabular}

Legend:VR, variables; SD, standard deviation; DI2, physical function; DI3, physical function; DI4, pain; DI5, general health; DI6, emotional welfare; DI7, emotional function; DI8, social function; DI9, energy/feed;TT, total KDQOL-SF

Correlating the data used as presented in Table 6, according to Spearman's correlation between hemodialysis time, associated diseases, respiratory muscle strength, peak expiratory flow and functionality, there are only weak and moderate correlations. There was a moderate correlation ( $\mathrm{r}$ between 0.4 and 0.69 ) that the lower the MIP obtained, the higher the values of MEP obtained, FIM and PEF obtained $(\mathrm{r}=-0.68 ; \mathrm{r}=-0.49 ; \mathrm{r}=-0.58$; respectively). Another finding was related to the MEP obtained and FIM, having a weak and positive correlation $(\mathrm{r}=0.39)$. The regression was carried through to verify the influence of the studied variables with the time of hemodialysis, being that the model was predicted only in the KDQOL-SF of significant form in the domains (D4) Work situation ( $\mathrm{p}<0.05)$, (D5) Cognitive function $(p<0.05)$ and (D9) Social support $(p<0.05)$. Multiple regression was performed and the model was determinant in the MIP variable obtained as a predictor of FIM $(\mathrm{p}<0.05)$. From multiple linear analysis, the domains (D18) Social Function and (D16) Emotional
Well-Being of KDQOL-SF were expressed significantly as FIM predictors $(\mathrm{p}<0.05)$. Considering MIP obtained as a factor, the multiple regression analysis resulted in a significant model that determined as predictors the variables MEP obtained and FIM $(\mathrm{p}<0.05)$. Multiple linear analysis for KDQOL-SF was significant and indicated that the domains (D1) List of Symptoms/Problems and (D12) Physical Performance are predictors of MIP obtained $(\mathrm{p}<0.05)$. Taking as a factor the PEF obtained, the multiple linear analysis indicated that the MIP variable obtained is predictive in a significant way $(\mathrm{p}<0.05)$. With KDQOL-SF, the significant model identified as predictive (D10) stimulus by the dialysis team $(\mathrm{p}<0.05)$, (D11) patient satisfaction $(p<0.05)$, (D15) general health $(p<0.05)$ and (D18) social function $(\mathrm{p}<0.05)$. From the multivariate regression analysis, it was noted that there was no significant impact on the variables (respiratory muscle strength, peak expiratory flow and functionality) considering two groups of hemodialysis time $\left(1^{\circ}\right.$ : less than 36 months and $2^{\circ}$ : more 
than 36 months) and associated diseases. The multivariate regression analysis of KDQOL-SF considering this time of hemodialysis and associated diseases as factors had a significant impact on dimensions (D8) Sleep, (D14) Pain and (D15) General health (Table 7).

Table 6 Spearman's correlation $(r)^{\prime}$ between hemodialysis time, associated diseases, respiratory muscle strength, peak expiratory flow and sample functionality

\begin{tabular}{llllll}
\hline & PEF obtained & FIM & MEP obtained & MIP obtained & THD \\
\hline FIM & $.286^{\prime}$ & & & \\
MEP obtained & $.300^{\prime}$ & $.396^{\prime}$ & & \\
MIP obtained & $-.589^{\prime}$ & $-.494^{\prime}$ & $-.682^{\prime}$ & \\
THD & $-.380^{\prime}$ & $.318^{\prime}$ & $.135^{\prime}$ & $.068^{\prime}$ \\
AD & $.186^{\prime}$ & $-.264^{\prime}$ & $.192^{\prime}$ & $.062^{\prime}$ & $-.327^{\prime}$
\end{tabular}

Legend: FIM, functional independence measure; MEP obtained, maximum expiratory pressure obtained within the sample; PImáx obtained, maximum inspiratory pressure obtained within the sample;THD, Time of hemodialysis; AD, associated diseases; PFE obtained, peak expiratory flow obtained within the sample

Table 7 Multivariate regression analysis considering KDQOL-SF $\mathbf{x}$ associated diseases and hemodialysis time as factors

\begin{tabular}{llll}
\hline Variable & OR & CI 95\% & P \\
\hline (D8)Sleep & 0.986 & $.973-.999$ & 0.034 \\
(DI4) Pain & 1.063 & I.00I - I.I28 & 0.046 \\
(DI5) General health & 0.97 & $.998-.998$ & 0.037
\end{tabular}

Legend: OR, odds ratio; $\mathrm{Cl}, 95 \%$ confidence interval; $\mathrm{p}$, significance value $(p<0.05)$

\section{Discussion}

Data from the last decades show high prevalence of systemic arterial hypertension (SAH) and diabetes mellitus (DM) in patients with CRD. ${ }^{15}$ Thus, the present study also corroborates this, although with greater emphasis on HBP, followed by its association with DM and a lower rate for DM exclusively, following the same line of studies found in the Northeastern region of the country. ${ }^{16}$ However, in the last Brazilian Chronic Dialysis Survey in $2017^{4}$ it was noted that the biggest reason for admission to dialysis was Diabetes Mellitus, although it is not in greater numbers in this population. It is evident that both etiologies mentioned above are silent chronic ailments, which are commonly discovered due to some complication, such as infarction, hypoglycemia and renal failure. Therefore, the importance of early diagnosis for quality treatment and continuous monitoring in order to avoid cardio-cerebrovascular diseases. ${ }^{17,18}$ Intimately linked to etiologies are nutritional diet and the level of physical activity developed, which over the years has accommodated itself to more industrialized foods and sedentarism, causing changes in weight and mass distribution. The sample in question presents the level of obesity, however the level of physical activity of these individuals was not collected, but the Brazilian literature shows that about 59 to $78 \%$ of them are sedentary, due to physical and psychological changes derived from uremia. These factors predispose to higher rates of metabolic syndromes. ${ }^{19,20}$

These findings show the importance of emphasizing the training, awareness and vigilance offered by a team of professionals, as a form of interdisciplinary care demonstrating the importance of changes in living habits (food and physical) to improve care for this population. ${ }^{21,22} \mathrm{~A}$ barrier in this public is the provision of time (usually 12 hours per week) for their hemodialysis treatment, which can be a limitation to diet flexibility and regular exercise. ${ }^{23,24}$ This study shows that individuals spend much of their time (about 12 hours a week) with other renal patients and with the multiprofessional support team. Santos et al. ${ }^{25}$ from an ethnographic perspective approach the good impact of this assiduous frequency in the place where hemodialysis treatment is performed, which generates a relationship of affection and companionship. Noting that although it is a long time spent in treatment, the environment being surrounded by people who understand their problems gives them a greater propensity for new possibilities. Justifying the positive impact between time of hemodialysis and the social support presented in QL. It is a fact that hemodialysis treatment causes a vicious cycle of functional decline. Therefore, several studies indicate that these patients under treatment have reduced functional capacity, with impact on the development of basic day-to-day activities. ${ }^{8}$ However, this functional impact was not found in this study, since the value of FIM resulted in complete independence (118.13), corroborating the study by Oller et al. ${ }^{26}$ who applied this questionnaire to 214 patients with similar characteristics and obtained a similar result of 118.33 points. This is possibly justified by drug intervention to maintain its functionality in the best possible way, as well as the impact of family income and level of schooling, which when seen in the literature, both are in a better state of functionality. ${ }^{27}$

Added to the reduction in functional capacity, it is true that there is a reduction in pulmonary function. In the literature, there are about $40-50 \%$ of the expected values for the healthy population, and this is exactly what was found in the present study, where there was a very significant deficit in the strength of the respiratory muscles and peak expiratory flow. ${ }^{28,29}$ It is worth noting that the lower the MIP value, the better the muscle performance. The negative correlation, evidenced in this study, between MIP, FIM and MEP, further strengthens the idea that the greater the inspiratory and expiratory muscle balance, the better its functionality. ${ }^{30}$ The quality of life of the chronic renal patient is directly affected by the way the disease is confronted and its consequences, in the treatment time and its associated diseases, variables that were seen significant statistical correlation between the data, reinforcing the study by Oliveira et al..$^{31}$ The peculiarity of the choice of the specific questionnaire for the chronic renal population, gave us a better targeting of the characteristics of chronic renal patients, in an effective and direct way, having low cost and easy understanding. ${ }^{32}$ In our results we observed that there is congruence with the studies of Lopes et al. ${ }^{31,33}$ since in our research, the most negatively affected domain is the dimension (D4) Work situation. This domain inside in reporting what the work status refers to the interference of the disease with the current work status. Since only 2 individuals in our sample are still working, this possibly leads to a decline in physical and mental aspects. Corroborating evidently in the findings of the study with a strong decrease in dimension values (D12) Physical Function, (D13) Physical Function and (D17) Emotional Function. 
The second dimension with the greatest negative impact was (D3) renal disease overload, which according to Gonçalves et al. ${ }^{34}$ who also obtained this result, reports that the dimension itself with a mean of less than 50 points is not able to express the tired, depressed appearance and complaints of symptoms of these individuals. The third most affected dimension is (D11) sexual function, which in the literature usually does not have any significant impact on the individual's life, but which in the present study was among the three dimensions with the lowest mean, and the highest negative impact on QL.

In the study by Santos et al. ${ }^{35}$ in agreement with this finding, it justifies possible misunderstandings in the answers to the questionnaire, due to the omission of correct information by the patient, to the extent that there may be a feeling of embarrassment about his sexuality. However, in the sample under discussion, due to information collected while filling out the KDQOL-SF, individuals feel their sexuality directly affected by their illness. As previously discussed, on the great impact on the work situation, there is another factor directly linked, the time of hemodialysis, being justified from the principle of treatment (HD), which makes it impossible to compromise the workload. Studies still associate the absence of work with cognitive deficit due to day-to-day low activities. However, despite the depreciative impacts of longer time in hemodialysis treatment, the individual ends up finding his social support with his caregivers inside and outside his hemodialysis clinics. ${ }^{36,37}$ The impact that the domain (D8) Sleep received from the time of hemodialysis and associated diseases, according to Parvan and collaborator $^{38}$ is related to intense fatigue, which can cause insomnia, also associated with concerns about prognosis, low schooling and advanced age. Another dimension was affected by these two factors, which was (D14) Pain, controversial in the literature, which ensures that individuals are under the effects of various analgesic drugs. However, it should be taken into account that the sample includes mature adult individuals, who may present a higher level of physical deterioration. ${ }^{34,39}$

The QL questionnaire brings us an important fact when it clarifies that THD and its associated diseases have an impact on how these individuals view their general health status (dimension 18). They are patients who find themselves ill most of the time, with little confidence in their prognosis and little will to live. It calls attention to the importance of integral care in order to be approached by the multidisciplinary team, with emphasis on nutritional and psychological care, being one of the most complaining issues during the interviews, due to food restrictions. ${ }^{40}$ The study presented limitations regarding the investigation of the functionality and dimensions of the affected KDQOL-SF of individuals, where the literature brings as an influence the family income and quality of life prior to diagnosis, information that was not collected. A different portrait factor in the present study is on the service model of data collection (private/convicted hospital), since the studies usually bring public institutions, which may have interfered in the results of the study variables.

\section{Conclusion}

It was concluded that there was a decline in respiratory functional parameters, both in respiratory muscle strength and peak expiratory flow. Although there was no decline in functionality, in general. The quality of life showed difficulty in maintaining paid work concomitantly with therapy, followed by low sexual performance which is very much linked to psychological impairment. Being the dimensions Pain, General Health and Sleep when related to hypertension and diabetes mellitus, the most negatively affected. Finally, the longer the hemodialysis treatment time, the greater the social comfort and acceptance of prognosis. The study opens several other lines of research such as the correlation between each dimension of the quality of life questionnaire. Understand other factors that may influence the decline in their sexual function. As well as the cost-effectiveness of a physical exercise program, during or without hemodialysis, for the population in question.

\section{Acknowledgments}

The Kidney Hospital, symbolized by Igor Laytynher, which enabled the collection of data for research. I would also like to thank the multiprofessional team that welcomed me in the most beautiful way possible, and the individuals in the sample, always receptive.

\section{Conflicts of interest}

There is no conflict of interest of any kind.

\section{References}

1. Menezes FG. Panorama of hemodialysis treatment financed by the Single Health System - An economic perspective. J Bras Nefrol. 2015;37(3):367378 .

2. Malta DC. Chronic non-communicable diseases and the use of health services: analysis of the National Health Survey in Brazil. Rev Saúde Pública. 2017.

3. Brazilian society of nephrology. Chronic Renal Disease in Brazil. 2017.

4. Thomé FS. Brazilian Chronic Dialysis Survey 2017. J Bras. Nefrol. 2019;41(2):208-214.

5. KDIGO 2012. Clinical practice guideline for the evaluation and management of chronic kidney disease. Kidney Int Suppl. 2013;3:1-150.

6. Ministry of health. Clinical Guidelines for the Care of Patients with Chronic Renal Disease - DRC in the Single Health System / Ministry of Health. Secretariat of Health Care. Department of Specialized and Thematic Attention. - Brasília: Ministry of Health, 2014, p. 37.

7. Fassbinder Tânia Regina Cavinatto, Winkelmann Eliane Roseli, Schneider Juliana, et al. Functional capacity and quality of life of patients with chronic predialytic renal disease and on hemodialysis - A cross-sectional study. J Bras Nefrol. 2015;37(1):47-54.

8. Santos BP, Oliveira VA, Soares MC, et al. Kidney disease and relationship with hemodialysis. ABCS Health Sci. 2017;42(1):8-14.

9. Cockroach NERRC. Daily Relationship and Quality of Life of Patients with Chronic Renal Disease. J Bras Nefrol. 2015.

10. Riberto M, Miyazaki MH, Jucá SSH, et al. Validation of the Brazilian Version of the Functional Independence Measure. PHYSIATR ACT. 2004;11(2):72-77.

11. Duarte PS, Ciconelli RM, Sesso R. Cultural adaptation and validation of the "Kidney Disease and Quality of Life-Short Form (KDQOL-SF 1.3)" in Brazil. Braz J Med Biol Res. 2005;38:261-270.

12. Neder JA, Andreoni S, Castelo-Filho A. Reference values for lung function tests. I. Static volumes. Braz J Med Biol Res. 1999;32(6):703-717.

13. Souza RB. Maximum static respiratory pressures. In: Pereira CAC, et al., editors. Guidelines for pulmonary function tests. $1^{\text {st }}$ Ed. São Paulo: Unifesp, 2002, p.15F5-58.

14. Hays RD, Kallich J, Mapes D. Kidney Disease Quality of Life Short Form (KDQOL-SF TM). Version 1.3: A Manual for Use and Scoring. Santa Monica, CA: RAND Corporation, 1997.

15. Eknoyan G, Lameire N, Eckardt K, et al. KDIGO 2012 clinical practice guideline for the evaluation and management of chronic kidney disease. Kidney Int. 2013;3:5-14.

16. Oliveira Junior HM, Formiga FFC, Alexandre CS. Clinicalepidemiological profile of patients on chronic hemodialysis program in João Pessoa - PB. J Bras Nefrol. 2014;36(3):367-374. 
17. Machado, Gabriela Rocha Garcia, Pinhati. Dialysis treatment in patients with chronic renal failure. Cadernos UniFOA, Volta Redonda. 2014;26:137-148.

18. Crews Deidra C, Bello Aminu K, Saadi Gamal. 2019 World Kidney Day Editorial - burden, access, and disparities in kidney disease. J Bras Nefrol. 2019;41(1):1-9.

19. Araújo J, Neto V, Anjos E. Chronic renal patients everyday on hemodialysis: expectations, modifications and social relations. Revista de Pesquisa: Cuidado é Fundamental Online. 2016;8(4):4996-5001.

20. Ribeiro KSMA, Mota ESG, Rocha RF. Profile of chronic renal patients in hemodialysis treatment in a city of northern Minas Gerais. Norte Mineira de Enfermagem magazine. 2018;7(1):61-72.

21. Kovesdy CP, Czira ME, Rudas A, et al. Obesity and Kidney Disease: Hidden Consequences of the Epidemic. American Journal of Hypertension. 2017;30(3):85-92.

22. Sarmento Luana Rodrigues, Fernandes Paula Frassinetti Castelo Branco Camurça, Bridges Marcelo Ximenes, et al. Prevalence of primary causes of terminal chronic renal disease (TKD) clinically validated in a capital city of Northeast Brazil. J Bras Nefrol. 2018;40(2):130-135.

23. Andrade LS, Dalboni MA, Carvalho JTG, et al. In vitro effect of uremic serum on barrier function and inflammation in human colonocytes. $J$ Bras Nefrol. 2018;40:2016-23.

24. Nitta K, Masakane I, Hanafusa N, et al. Annual dialysis data report 2017, JSDT Renal Data Registry. Ren Replace Ther. 2019;5:53.

25. Santos Viviane Fernandes Conceição dos, Borges Zulmira Newlands, Lima Sônia Oliveira, et al. Perceptions, meanings and adaptations to hemodialysis as a liminal space: the patient's perspective. Interface (Botucatu). 2018;22(66):853-863

26. Oller GASAO, Ribeiro RCHM, Travagim DSA, et al. Functional independence in patients with chronic renal disease in hemodialysis treatment. Rev Latino-Am. Nursing. 2012;20(6):1033-1040.

27. Leimig MB, Lira RT, Peres FB, et al. Quality of life in people with chronic renal disease on hemodialysis. Rev Soc Bras Clin Med. 2018;16(1):30-36.

28. Posser Simone Regina, Cecagno-Zanini, Sheila Cristina, et al. Functional capacity, pulmonary and respiratory muscle strength in individuals undergoing hemodialysis. Fisioter mov. 2016;29(2):343-350.
29. Campos Nataly Gurgel, Marizeiro Débora Fortes, Florêncio Ana Carolina Lins, et al. Effect of respiratory muscle training in patients undergoing hemodialysis: a systematic review. Motri. 2018;14(1):232-239.

30. Bae YH, Lee SM, Jo JI. Aerobic training during hemodialysis improves body composition, muscle function, physical performance, and quality of life in chronic kidney disease patients. J Phys Ther Sci. 2015;27:14451449 .

31. Oliveira APB, Schmidt DB, Amatneeks TM, et al. Quality of life in hemodialysis. J Bras Nefrol. 2016;38(4):411-420.

32. Carrillo-Algara AJ, Torres-Rodríguez, GA, Leal-Moreno CS. Scales to assess quality of life in people with advanced chronic kidney disease: integrative review. Enferm Nefrol Madrid. 2018;21(4):334-347.

33. Lopes Jéssica Maria, Fukushima Raiana Lídice Mor, Inouye Keika, et al. Quality of life related to the health of chronic renal patients on dialysis. Acta paul. enferm. 2014;27(3):230-236.

34. Gonçalves Fernanda Aguiar, Dalosso Ingrid Fernandes, Borba Jéssica Maria Camargo, et al. Quality of life of chronic renal failure patients on hemodialysis or peritoneal dialysis: comparative study in a reference service of Curitiba - PR. J Bras Nefrol. 2015;37(4):467-474.

35. Santos GD, Castilho MS, Viso BF, et al. Quality of life of hemodialysis patients in the city of Mogi das Cruzes. Diagnosis Treatment. 2014;19:3-9.

36. Barbosa Jefferson Belarmino Nunes, Moura Elaine Cristina Santa Cruz de, Lira Celine Lorena Oliveira Barboza de, et al. Quality of life and duration of hemodialysis in patients with chronic renal disease (CRD): a crosssectional study. Fisioter mov. 2017;30(4):781-788.

37. Everling J. Events associated with hemodialysis and perceptions of discomfort with renal disease. Av enferm Bogotá. 2016;34(1):48-57.

38. Sanchez-Gonzalez JC. Analysis of quality of life in patients with renal replacement therapy: influence of analytical parameters and socioclinios. Enferm Nefrol Madrid. 2019;22(2):159-167.

39. Parvan K, Lakdizaji S, Roshangar F, et al. Quality of sleep and its relationship to quality of life in hemodialysis patients. J Caring Sci. 2013;2(4):295-304.

40. Cavalcante Milady Cutrim Vieira, Lamy Zeni Carvalho, Lamy Filho Fernando, et al. Factors associated with the quality of life of adults on hemodialysis in a city in northeastern Brazil. J Bras Nefrol. 2013;35(2):7986. 